\title{
Penerapan Ketentuan Special and Differential Treatment dalam World Trade Organization terhadap Pembangunan dan Perdagangan Internasional
}

\author{
Annisa Sabila Hasanie*; Bernard Sipahutar \\ Fakultas Hukum Universitas Jambi \\ *Coresponding author: annisahasanie@outlook.com \\ Submission : 14 Juli 2020 \\ Revision : 31 Oktober 2020 \\ Publication : 20 November 2020
}

\begin{abstract}
Globalization and liberalization have caused many economic actors from developing countries to be eliminated because they cannot compete with economic actors from developed countries. Developing countries are increasingly dependent on developed countries and international economic institutions such as the IMF and World Bank. The World Trade Organization as a world trade organization pays special attention to the interests of developing countries through the provisions of Special and Differential Treatment (S\&D). Developing countries under certain conditions can be given special treatment that is more beneficial in their trade relations with developed countries. However, the provisions of $S \& D$ to date are still unfair and have a significant impact on the development progress of developing countries as expected. If seen based on MDGs Report data, many developing countries are still in a low level of economic prosperity.
\end{abstract}

Keywords: Developing Countries; Special and Differential Treatment; World Trade Organization

\footnotetext{
Abstrak

Globalisasi dan liberalisasi telah menyebabkan banyak pelaku ekonomi dari negara-negara berkembang tersingkir karena kalah bersaing dengan para pelaku ekonomi dari Negara-negara maju.
} 
Negara sedang berkembang semakin tergantung pada negara-negara maju dan lembaga-lembaga ekonomi internasional seperti IMF dan World Bank. World Trade Organization sebagai organisasi perdagangan dunia memberi perhatian khusus kepada kepentingan negara-negara berkembang melalui ketentuan Special and Differential Treatment $(S \& D)$. Negara-negara berkembang dalam kondisi tertentu dapat diberi perlakuan-perlakuan khusus yang lebih menguntungkan dalam hubungan dagang mereka dengan negaranegara maju. Namun, ketentuan $S \& D$ hingga saat ini masih dirasa kurang adil dan berdampak signifikan terhadap kemajuan pembangunan Negara-negara berkembang seperti yang diharapkan. Berdasarkan data MDGs Report pada tahun 2000-2015 banyak Negara sedang berkembang masih dalam tingkat kesejahteraan ekonomi yang rendah.

Kata Kunci: Negara Berkembang; Special and Differential Treatment; World Trade Organization

\section{A. Pendahuluan}

Sejak diberlakukannya Perjanjian World Trade Organization (WTO), globalisasi dan liberalisasi ekonomi yang didukung oleh kemajuan teknologi transportasi, komunikasi, industri berlangsung semakin cepat. ${ }^{1}$ Dapat dikatakan bahwa tidak ada satu Negara pun yang dapat menghindar dari proses globalisasi dan liberalisasi ekonomi tersebut. ${ }^{2}$

Hubungan tersebut membutuhkan adanya penataan yang baik, agar tercipta suatu tata ekonomi internasional yang ideal sesuai tujuan dari penyelenggaraan hubungan ekonomi internasional tersebut. Untuk menunjang setiap tata ekonomi akan diperlukan pelaku-pelaku ekonomi, organisasi ekonomi, administrasi ekonomi, pengambilan keputusan, kerjasama (interaksi) dan norma-norma hukum ekonomi yang

1 Muhammad Sood. Hukum Perdagangan Internasional. Ed. 2, Cet. 4, Rajawali Pers. Jakarta. 2019. hal. 1.

2 Huala Adolf. Hukum Perdagangan Internasional. Rajawali Pers. Jakarta. 2014. hal. 19.

Uti Possidetis: Journal of International Law, Vol. 1, No. 3 (2020) 
keseluruhannya membentuk tatanan atau tata ekonomi yang bersangkutan. ${ }^{3}$

Pengaturan hukum internasional dapat digunakan untuk mendorong terjadinya pertumbuhan ekonomi yang tinggi, menjaga stabilitas ekonomi dan memeratakan kesejahteraan ekonomi secara adil untuk seluruh bangsa. Maka dari itu dalam merumuskan kebijakan-kebijakan perdagangan internasional, WTO juga memberi perhatian khusus kepada kepentingan negara-negara sedang berkembang dan LDCs (least developed countries).

Pada prinsipnya Perjanjian WTO terus memodifikasi dan memperluas sistem GATT 1947. Akan tetapi, meskipun telah ada berbagai modifikasi pengaturan ekonomi internasional dan di bawah Perjanjian WTO kepentingan ekonomi negara-negara sedang berkembang telah diperhatikan. Meskipun berbagai alat proteksi bagi kepentingan ekonomi negara-negara sedang berkembang memang telah diberikan berdasar kesepakatan-kesepakatan WTO melalui ketentuan-ketentuan Special and Differential Treatment (S\&D). Awal disepakatinya ketentuan tersebut dilandasi pada dua hal yaitu, sebagai bentuk keadilan dan sebagai alat pembangunan. Akan tetapi, dalam kenyataannya ternyata tidak membuat keadaan ekonomi negara-negara sedang berkembang segera meningkat. Bahkan akibat kalah bersaing dengan industri negara-negara maju, banyak industri sedang berkembang tersingkir, sehingga menyebabkan memburuknya ekonomi negara-negara sedang berkembang.

Ketentuan tersebut bertujuan mengatur perlakuanperlakuan khusus (preferential status) kepada negara-negara sedang berkembang dan LDCs. Akan tetapi, dalam implementasi ketentuan-ketentuan WTO yang mengakomodasikan dan memberi perlakuan khusus yang berbeda kepada negara-negara sedang berkembang sering

${ }^{3}$ Laporan Penelitian "Asas-asas Hukum Internasional Yang Mendukung Tata Ekonomi Internasional Baru". Kerjasama Proyek Penelitian dan Pengembangan Politik Luar Negeri Republik Indonesia dengan Pusat Penelitian Perkembangan Hukum Lembaga Penelitian UNPAD. Bandung. 2016. hal. 2.

Uti Possidetis: Journal of International Law, Vol. 1, No. 2 (2020) 
terhambat oleh sikap negara-negara maju yang sering kurang mendukung. Terlebih lagi ketentuan $S \& D$ tersebut tidak bersifat mengikat. Perlakuan khusus yang harus diberikan kepada negara-negara sedang berkembang oleh negara-negara maju dianggap hanya bersifat sukarela, sehingga sering tidak efektif, karena implementasinya tergantung dari itikad baik negara-negara maju.

Masalah ketimpangan ekonomi global yang terjadi hingga saat ini antara lain disebabkan oleh pengaturan hubungan terkait ekonomi internasional yang belum mengakomodasikan kepentingan negara-negara sedang berkembang, khususnya negara-negara Asia, Afrika, Amerika Latin yang dulu terjajah dan baru merdeka. Pengaturan ekonomi internasional, khususnya di bawah lembaga-lembaga ekonomi Bretton Woods, yakni IMF, World Bank dan GATT 1947, masih banyak menggunakan prinsip-prinsip hukum ekonomi internasional klasik, sehingga menguntungkan negara-negara industri maju dan menyebabkan negara berkembang harus bergantung dengan ekonomi negara maju. Hal tersebut menyebabkan tingginya kesenjangan dari sisi kesejahteraan antara negara-negara maju dan negara-negara sedang berkembang. Pengaturan hubungan ekonomi internasional sampai saat ini juga masih sering dikritik karena belum maksimal dalam mengakomodasikan kepentingan negara-negara sedang berkembang.

\section{B. Pembahasan}

\section{Keterkaitan antara Perdagangan dan Pembangunan Menurut WTO}

GATT 1947 telah mengatur kepentingan pembangunan negara-negara sedang berkembang dan miskin melalui Bagian IV (Pasal-pasal XXXVI, XXXVII dan XXXVIII) GATT 1947 di bawah judul Perdagangan dan Pembangunan. Bagian VI GATT 1947 tersebut ditambahkan pada tahun 1965 sebagai respon terhadap ketidakadilan yang dialami negara-negara sedang berkembang dalam sistem pengaturan hubungan ekonomi internasional berdasar lembaga-lembaga ekonomi Bretton 
Woods, yang salah satu di antaranya adalah GATT 1947. Bagian IV GATT 1947 tersebut memuat tentang penegasan (mengingat) bahwa tujuan utama dari GATT 1947 meliputi peningkatan taraf hidup dan pembangunan ekonomi yang progresif dari semua peserta, dan pencapaian dari tujuan ini sangat mendesak bagi negara-negara yang belum maju. Diperlukan tindakan individual dan gabungan untuk mendorong pembangunan ekonomi negara-negara sedang berkembang peserta GATT 1947 agar dapat meningkatkan standar hidup rakyat mereka secara cepat. Bagian Keempat GATT 1947 juga memuat komitmen negara-negara maju untuk memberi perlakuan yang lebih baik bagi negara-negara sedang berkembang atau menerima (mengakui) bahwa negara-negara sedang berkembang belum dapat dibebani kewajiban yang sama seperti yang dibebankan pada negara-negara maju. Namun kelemahan dari ketentuan-ketentuan untuk membantu dan memberi perlakuan yang lebih baik kepada negara-negara sedang berkembang tersebut kebanyakan bersifat kesukarelaan dan bukan merupakan kewajiban yang mengikat.

Kepentingan pembangunan juga tidak dilepaskan oleh WTO sebagai penerus GATT 1947. Berkaitan dengan kepentingan pembangunan, bagian konsideran Perjanjian WTO antara lain menyebutkan sebagai berikut :

"Recognizing that their relations in the field of trade and economic endeavour should be conducted with a view to raising standards of living, ensuringfull employment and a large and steadily growing volume of real income and effective demand, and expanding the production of and trade in goods and services, while allowing for the optimal use of the world's resources in accordance with the objective of sustainable development, seeking both to protect and preserve the environment and to enhance the means for doing so in a manner consis tent with their respective needs and concerns at different levels of economic development. Recognizingfurther that there is need for positive efforts designed to ensure that developing countries, and especially the least developed 
among them, secure a share in the growth in international trade commensurate with the needs of their economic development."

Peter Van den Bossche juga mengemukakan bahwa tujuan akhir dari WTO adalah sebagai berikut:

a. Meningkatkan standar hidup;

b. Terciptanya kesempatan kerja;

c. Pertumbuhan pendapatan yang riil dan permintaan terhadap barang dan jasa yang efektif; dan

d. Meningkatkan produksi dan perdagangan dan jasa. ${ }^{4}$

Dalam menangani masalah perdagangan dalam hubungannya dengan pembangunan, dalam lingkup organisasi WTO pada tahun 1995 dibentuk Komisi Perdagangan dan Pembangunan (The Committee on Trade and Development), yang berada di bawah Dewan Umum WTO. Komisi Perdagangan dan Pembangunan WTO membentuk sebuah Sub-Komisi tentang negara-negara yang masih tertinggal ( $L D C S$ ), yang bertujuan untuk meyakinkan (menekankan) bahwa permasalahan dan kepentingan negara-negara tersebut diberi perhatian khusus dalam kerangka WTO. Komisi Perdagangan dan Pembangunan WTO menangani pemberitahunan-pemberitahunan tentang:

1. Program-program Generalized System of Preferences (GSP), yakni pemberian hambatan-hambatan dagang yang lebih rendah oleh negara-negara maju untuk produkproduk negara-negara sedang berkembang.

2. Preferential arrangements di antara negara-negara sedang berkembang seperti the Southern Common Market in Latin America (MERCOSUR), the Common Market for Eastern and Southern Africa (COMESA), dan the ASEAN Free Trade Area (AFTA).

Berdasar data tahun 2018 masih terdapat sejumlah 47 least developed countries (LDCs) yang belum mendapatkan

${ }^{4}$ Peter van den Bossche. Pengantar Hukum WTO (World Trade Organization). Yayasan Obor. Jakarta. 2010. hal. 91.

Uti Possidetis: Journal of International Law, Vol. 1, No. 3 (2020) 
keadilan dalam tatanan ekonomi dunia. ${ }^{5}$ Berdasar hak-hak khusus tertentu yang bersifat menguntungkan, Perjanjian WTO juga mengatur tentang kepentingan negara-negara sedang berkembang (developing countries) dan negara-negara yang masih tertinggal (least developed countries - LDCs). Namun demikian WTO tidak mengatur tentang kriteria negara-negara sedang berkembang dan negara-negara yang belum maju ( $L D C s$ ) tersebut.

Berkaitan dengan hal itu, Putaran Doha yang dimulai tahun 2001 hingga tahun 2020 masih berjalan lambat dan tersendat-sendat, karena perbedaan kepentingan negaranegara maju dan negara-negara sedang berkembang sering muncul menjadi penghambat tercapainya kesepakatan di antara para anggota WTO. Salah satu kepentingan negaranegara sedang berkembang yang kurang diperhatikan dalam perundingan adalah "pembangunan". Sejak "Doha Development Agenda" diluncurkan tahun 2001, negara-negara sedang berkembang telah mempertanyakan, di manakah letak "pembangunan" dalam agenda perundingan. Negara-negara maju nampaknya berusaha menanggalkan agenda pembangunan dan tidak menjadikan pembangunan sebagai landasan perundingan WTO Putaran Doha.

Setelah berlakunya Perjanjian WTO semua negara seolah "dipaksa" melakukan liberalisasi ekonomi, dengan keyakinan bahwa melalui liberalisasi ekonomi akan tercapai efisiensi produksi dan sumber daya alam dapat dimanfaatkan secara maksimal demi kesejahteraan penduduk dunia. Namun keyakinan tersebut runtuh setelah perjanjian WTO berjalan beberapa tahun. Liberalisasi ekonomi berdasar perjanjian WTO ternyata hanya memberi kemakmuran ekonomi pada segelintir elite di negara-negara maju, namun banyak menimbulkan kesengsaraan pada mayoritas orang, khususnya rakyat negara-negara sedang berkembang.

5 United Nations Committee for Development Policy, List of Least DevelopCountries, https://www.un.org/development/desa/dpad/ wpcontent/uploads/sites/45/publication/ldc list.pdf, diakses pada 29 Mei 2020, Pukul 19.21 WIB.

Uti Possidetis: Journal of International Law, Vol. 1, No. 2 (2020) 


\section{Penerapan Ketentuan Special and Differential Treatment dalam Mendukung Kemajuan Pembangunan Negara Berkembang}

Pada bagian Pembukaan (Konsideran) Persetujuan tentang Pembentukan WTO antara lain dinyatakan adanya pengakuan bahwa diperlukan adanya upaya positif yang dirancang untuk menjamin negara-negara sedang berkembang, dan khususnya LDCs, agar mereka dapat mengamankan peranannya dalam pertumbuhan perdagangan internasional sesuai (sepadan) dengan kebutuhan pembangunan ekonomi mereka. ${ }^{6}$ Kemudian dalam berbagai persetujuan yang merupakan lampiran dari Persetujuan Pembentukan WTO diatur berbagai alat proteksi yang ditujukan untuk melindungi sementara waktu ekonomi negara-negara sedang berkembang sejak berlakunya liberalisasi ekonomi. Dalam hal kebijakan dagang, negaranegara sedang berkembang dan LDCs sebagai anggota WTO ditinjau setiap enam tahun, sedangkan negara-negara maju dua dan empat tahun.

Atas dasar itu akhirnya diakomodasi kepentingan Negara berkembang oleh $W T O^{7}$ melalui sejumlah kebijakan yang Special and Differential Treatment (S\&D).

Diadopsinya $S \& D$ melalui perjanjian $W T O$ atas dasar prinsip bahwa liberalisasi perdagangan bukan merupakan

6 Butir kedua 2 Konsideran dari Persetujuan Pembentukan WTO menentukan: Recognizing further that there is need for positive efforts designed to ensure that developing coutries, and especially the least-developed among them, secure a share in the growth in international trade commensurate with the needs of their economic development.

7 Secara umum, WTO mengklasifikasi anggota-anggotanya ke dalam dua kelompok: negara-negara maju (developed countries) dan negara-negara berkembang (developing countries). Kelompok yang terakhir mencakup juga negaranegara terbelakang/miskin (leastdeveloped countries). Meskipun demikian, WTO tidak memberikan definisi mengenai negara maju dan negara berkembang. Hal ini sangat tergantung negara-negara anggota untuk memasukkan dirinya ke dalam kelompok yang mana. Nevertheless, the WTO provides no definitions of developed and developing countries.

Uti Possidetis: Journal of International Law, Vol. 1, No. 3 (2020) 
upaya dalam mencapai tujuan tetapi sebagai alat dalam mencapai tujuan tersebut, yaitu pertumbuhan dan pembangunan ekonomi seluruh negara anggotanya. ${ }^{8}$ Selain itu, ketentuan-ketentuan tersebut menunjukkan pengakuan bahwa adanya ketimpangan pembangunan yang dicapai oleh negara-negara anggota WTO, oleh sebab itu diperlukan perangkat-perangkat berisikan kebijakan untuk mendukung pertumbuhan dan pembangunan ekonomi yang berbeda pula. ${ }^{9}$ Maka beberapa Perjanjian $W T O$ memuat 145 ketentuan $S \& D$, 107 di antaranya diadopsi, dan secara khusus 22 ketentuan tersebut ditujukan untuk negara terbelakang (least-developed country Members). ${ }^{10}$

Ketentuan $S \& D$ yang bersifat menguntungkan bagi negara-negara sedang berkembang dan $L D C s$ tersebut sejalan dengan salah satu tujuan dari Perundingan GATT Putaran Uruguay, yakni untuk menciptakan perdagangan bebas dunia yang memberi sebagian keuntungan negara-negara sedang berkembang. Oleh karena itu dalam perdagangan bebas di bawah WTO tidak boleh ada yang kalah dan yang menang, tetapi perdagangan bebas tersebut harus memberi keuntungan kepada semua negara baik negara-negara maju maupun negara-negara sedang berkembang. Maka negaranegara sedang berkembang perlu diberi hak-hak istimewa atau kelonggaran-kelonggaran dalam melaksanakan persetujuan $W T O$, agar tidak dirugikan dalam perdagangan bebas WTO akibat industri mereka kalah bersaing dengan industri negara-negara maju.

${ }^{8}$ Article XXXVI: 1(e) GATT berbunyi: “...recognising that international trade as a means of achieving economic and social advancement..."

${ }^{9}$ The Preamble of the Marrakesh Agreement Establishing the WTO menyatakan, "...there is need for positive efforts designed to ensure the developing countries and especially the least developed among them, secure a share in the growth in international trade commensurate with their needs of their economic development".

10 The WTO Secretariat, Implementation of Special and Differential Treatment Provisions in WTO Agreements and Decisions, Committee on Trade and Development, WT/COMTD/W/77( 25 Oktober 2000), hal. 3.

Uti Possidetis: Journal of International Law, Vol. 1, No. 2 (2020) 
Sejak Perjanjian WTO memuat ketentuan-ketentuan S\&D bahkan hingga saat ini, banyak yang mengungkapkan keraguan termasuk mengenai penerapan implementasinya dalam mendorong negara berkembang untuk ikut serta dalam, dan mendapat manfaat yang berarti dari sistem perdagangan multilateral. ${ }^{11}$ Sebagaimana muncul dalam Laporan Committee of Trade and Development (CTD) 200412, keikutsertaan negara berkembang dalam perdagangan dunia dalam hal ekspor dan impor barang, hanya berkisar antara 20 sampai 30 persen, sedangkan kontribusi negara terbelakang justru menurun bahkan angka pertumbuhan impor melebihi ekspor. ${ }^{13}$ Realitas ini menguatkan pemikiran tentang adanya pembatasan negara berkembang dalam sistem perdagangan multilateral.

Kekhawatiran negara berkembang tentang efektivitas implementasi ketentuan-ketentuan $S \& D$ tidak hanya dilandasi oleh keterbatasan kemampuan negara berkembang, justru oleh hukum dari ketentuan-ketentuan $S \& D$ sendiri yang pada nyatanya tidak dapat ditegakkan. Sebagaimana pandangan

11 Edwini Kessie. "Enforceability of the Legal Provisions Relating to Special and Differential; Treatment under the WTO Agreements". Paper pada the Seminar on Special and Differential Treatment for Developing Countries. diselenggarakan oleh the WTO Committee on Trade and Development. 7 Maret 2000). hal. 1.

12 Antara tahun 2001 dan 2003, partisipasi negara berkembang dalam ekspor dunia naik sedikit dari 29\% menjadi 30\%, angka yang sama dengan tahun 2000. Selama periode 1990-2000, ekspor mereka naik dari 23\% menjadi 30\%. Pada tahun 2001 angka pertumbuhan ekspor mereka menurun -6\%. Pada tahun 2002 ekspor mereka relatif pulih, dan meningkat sebesar $17 \%$ pada tahun 2003, sehingga kontribusi ekspor mereka kembali menjadi 30\%, angka yang sama dengan tahun 2000. Sementara itu kontribusi mereka dalam impor dunia tetap pada angka $26 \%$ selama periode 2001-2003. Lihat Committee on Trade and Development, 'Participation of Developing Economies in The Global Trading System: Revision,' WT/COMTD/W/136/Rev.1, 6 Desember 2004.

13 Kontribusi negara terbelakang dalam ekspor dunia menurun 6\% pada tahun 2003, sementara impor tumbuh menjadi $20 \%$. Sedangkan angka pertumbuhan ekspor hanya 13\%.

Uti Possidetis: Journal of International Law, Vol. 1, No. 3 (2020) 
Edwini Kessie bahwa, "developing countries have always insisted on the legal enforceability of these provisions." 14

Selain itu hal ini mengakibatkan kesulitan implementasi dalam realita, karakter ketentuan S\&D yang tidak mempunyai daya mengikat secara hukum juga dapat mengakibatkan dampak yang serius. Sebagimana ketentuanketentuan S\&D tidak dapat ditegakkan secara efektif dalam proses penyelesaian permasalahan. Negara berkembang juga tidak dapat bersandar pada ketentuan-ketentuan S\&D untuk mendesak negara maju dalam menerapkan ketentuanketentuan tertentu, dan pada saat yang bersamaan mereka juga tidak mampu memperjuangkan hak-hak mereka berdasarkan ketentuan-ketentuan S\&D. Hal tersebut tertuang dalam CTD Report, negara berkembang menunjukkansikap kritisterhadap efektivitas penegakan ketentuan-ketentuan S\&D dan berpendapat tidak adanya kepastian sedikit pun bahwa ketentuan-ketentuan S\&D ini dapat ditegakkan dalam praktek penyelesaian sengketa. ${ }^{15}$

Keraguan negara berkembang tentang efektivitas ketentuan-ketentuan $S \& D$ dalam proses penyelesaian sengketa juga telah diungkapkan dalam hubungannya dengan tata cara interpretasi yang digunakan oleh para hakim. Tata cara penafsiran yang lebih ketat cenderung digunakan oleh para hakim dalam menginterpretasikan ketentuan-ketentuan tersebut. Seperti dinyatakan oleh Mesir, bahwa, "developing countries have been witnessing a trend towards stricter interpretation of S\&D provisions." 16

Ketentuan-ketentuan tersebut dapat membantu negara berkembang jikasecara efektif dapat ditegakkan dan diimplementasikan. Biarpun ketentuan-ketentuan $S \& D$ banyak

14 Kessie. Enforceability of the Legal Provisions. hal. 2.

15 Committee on Trade and Development. 'Concerns Regarding Special and Differential Treatment Provisions in WTO Agreements and Decisions,' WT/COMTD/W/66, 16 February 2000. 31.

16 General Council and Committee on Trade and Development. 'Special and Differential Treatment for Developing Countries in the Multilateral Trading System: Communication from Egypt,' T/GC/W/109; WT/COMTD/W/49. 5 November 1998. [93].

Uti Possidetis: Journal of International Law, Vol. 1, No. 2 (2020) 
dikritisi, negara berkembang beranggapan bahwa efektivitas terhadap penerapan implementasi dan penegakan hukum dalam ketentuan-ketentuan tersebut akan memacu pembangunan ekonomi, mengurangi angka kemiskinan, dan mendorongintegrasi negara berkembang menuju sistem perdagangan internasional sepenuhnya. ${ }^{17}$

Meskipun telah ada perubahan paradigma dan prinsip hukum dalam pengaturan hubungan ekonomi global, namun kenyataan masih menunjukkan bahwa masalah ketimpangan ekonomi global masih tetap ada dan kesenjangan tingkat kesejahteraan ekonomi antara rakyat di negara-negara maju dan rakyat di negara-negara sedang berkembang menjadi semakin jelas. Kesenjangan dalam tingkat perkembangan dan kesejahteraan ekonomi tersebut ternyata, juga menjadikan pengelompokan negara-negara ke dalam kelompok negara menjadi negara maju dan kelompok negara-negara sedang berkembang.

Data MDGs Report 2014 menunjukkan perbaikan yang berarti dari kualitas hidup penduduk dunia di berbagai bidang yang menjadi sasaran MDGs. Dalam ikhtisar (overview) MDGs Report 2014 yang ditulis Wu Hongbo (Under-Secretary-Geneml for Economic and Social Affairs) dinyatakan telah ada kemajuan yang sangat penting dalam pencapaian MDGs dan bahkan beberapa sasaran telah tercapai sebelum tahun 2015 . Namun juga diakui bahwa masih banyak kekurangan dalam pencapaian sasaran-sasaran MDGs. Bahkan di berbagai negara pencapaian sasaran $M D G s$ sangat terhambat karana adanya konflik bersenjata, ketidakstabilan politik dan bencana alam. ${ }^{18}$

17 Mengutip Douglas A. Irwin, Michael Hart dan Bill Dymond berpendapat sebaliknya bahwa usaha yang berkaitan dengan S\&D sepenuhnya bersifat politis dan bertentangan dengan fondasi-fondasi ekonomi. Lihat Michael Hart and Bill Dymond'Special and Differential Treatment and the Doha “Development" Round' (2003) 37(2) Journal of World Trade 395. 395.

18 The Millennium Development Goals Report 2014, https://www.un.org/millenniumgoals/2014\%20MDG\%20report

Uti Possidetis: Journal of International Law, Vol. 1, No. 3 (2020) 
MDGs tersebut telah terlaksana dan berakhir pada tahun 2015. Akan tetapi, masih menjadi pertanyaan besar apakah program pembangunan PBB akan berhenti setelah berakhimya $M D G s$ tahun 2015. Pada kata pengantar MDGs Report 2014, Sekretaris Jendral PBB, Ban Ki-Moon menyatakan bahwa negara-negara anggota PBB kini terikat untuk mendiskusikan tentang definisi "tujuan-tujuan pembangunan berkelanjutan" (Sustainable Development Goals) yang akan menjadi inti dari agenda "Pembangunan Universal" pasca tahun 2015. Pernyataan tersebut mengisyaratkan tentang kewajiban melanjutkan program pembangunan PBB pasca berakhimya $M D G s$ tahun 2015.

Meskipun telah ada landasan hukum yang kuat bagi program pembangunan internasional berkelanjutan, tanpa peran aktif Negara-negara sedang berkembang sebagai anggota WTO, agenda pembangunan internasional akan mudah dihapuskan oleh negara-negara maju. WTO merupakan organisasi yang berisikan "aturan-aturan atau rules", perjanjian tersebut haruslah mencerminkan kebutuhan anggota, namun realitasnya ditentukan oleh kekuatan politik negara-negara anggota. ${ }^{19}$ Pada masa sekarang ini, masyarakat internasional membutuhkan program pembangunan yang berkelanjutan guna membatasi laju liberalisasi ekonomi dunia beserta dampak negatifnya. Pembangunan dapat digunakan sebagai sarana untuk memeratakan kesejahteraan ekonomi global dan menciptakan keadilan dalam hubungan perdagangan internasional.

\section{Penutup}

Keterkaitan antara pembangunan dan perdagangan yaitu, sebagaimana GATT 1947 telah mengatur kepentingan pembangunan negara-negara sedang berkembang dan miskin.

/MDG\%202014\%20English\%20web.pdf, diakses pada 3 Juni 2020, Pukul 21.30 WIB.

19 Putra, Akbar Kurnia. "Agreement on Agricultue dalam World Trade Organization". Jurnal Hukum dan Pembangunan Tahun ke-46. No. 1. 1 Januari-maret 2001. hal. 98.

Uti Possidetis: Journal of International Law, Vol. 1, No. 2 (2020) 
Kepentingan pembangunan juga tidak dilepaskan oleh WTO sebagai penerus GATT 1947. Komisi Perdagangan dan Pembangunan WTO membentuk sebuah Sub-Komisi tentang negara-negara yang masih tertinggal ( $L D C S$ ), yang bertujuan untuk menekankan bahwa permasalahan dan kepentingan negara-negara tersebut perlu beri perhatian khusus dalam kerangka WTO. Di mana pembangunan merupakan salah satu upaya untuk memajukan perekonomian dan taraf hidup masyarakat di berbagai negara, khususnya di negara-negara sedang berkembang dan yang masih tertinggal.

Pengaruh penerapan ketentuan Special and Differential Treatment $(S \& D)$ belum sepenuhnya mendukung kemajuan pembangunan negara-negara berkembang dan negara-negara yang masih tertinggal ( $L D C s$ ). Hal tersebut dapat dilihat berdasarkan data Millenium Development Goals Report mengenai program pembangunan intemasional dalam jangka waktu tahun 2000 sampai 2015 bahwa target pencapaian pembangunan millenium nampaknya jauh dari capaian. Pelaksanaan Program Pembangunan Milenium itu sendiri sering kurang berjalan mulus karena ada kesan negara-negara maju sering menghambat dan tidak koperatif dalam melaksanakan hubungan perdagangan dengan Negara-negara berkembang, khususnya jika terkait dengan perlakuan khusus dan berbeda yang diberikan kepada Negara berkembang. WTO berkewajiban mengamati berbagai program yang berkaitan dengan perdagangan internasional, dengan adanya prinsip $S \& D$ ini membuat negaraberkembang mendapatkan perhatian lebih lanjut dalam mencapai tujuan-tujuan nasionalnya yaitu dengan hukum internasional sebagai wadahnya dan bagi negara maju diharapkan mempermudah pembangunan dan perdagangan internasional terutama pada mitra bisnisnya terutama negara berkembang. 


\section{Referensi}

\section{Buku-Buku}

Adolf, Huala. Hukum Perdagangan Internasional. Rajawali Pers. Jakarta. 2014.

Alatas, Ali. Memperkuat PBB Menghadapi Abad Ke-21. Universitas Gajah Mada. Yogyakarta. 2005.

Bossche, Peter van den, dkk. Pengantar Hukum WTO (World Trade Organization). Yayasan Obor. Jakarta. 2010.

Michael Hart and Bill Dymond, 'Special and Differential Treatment and the Doha "Development" Round' (2003) 37(2) Journal of World Trade 395, 395.

Sood, Muhammad. Hukum Perdagangan Internasional. Ed. 2, Cet. 4. Rajawali Pers. Jakarta. 2019.

Stiglitz, Joseph E. Globalization and Its Discontents. WW Norton \& Company. New York. 2002.

\section{Artikel atau Jurnal}

Committee on Trade and Development, 'Concerns Regarding Special and Differential Treatment Provisions in WTO Agreements and Decisions,' WT/COMTD/W/66, 16 February 2000. 31.

Committee on Trade and Development, 'Concerns Regarding Special and Differential Treatment Provisions in WTO Agreements and Decisions,' WT/COMTD/W/66, 16 February 2000. 31.

Edwini Kessie, "Enforceability of the Legal Provisions Relating to Special and Differential; Treatment under the WTO Agreements". Paper pada the Seminar on Special and Differential Treatment for Developing Countries, diselenggarakan oleh the WTO Committee on Trade and Development. 7 Maret 2000).

General Council and Committee on Trade and Development, 'Special and Differential Treatment for Developing 
Countries in the Multilateral Trading System: Communication from Egypt,' T/GC/W/109; WT/COMTD/W/49. 5 November 1998. [93].

General Council and Committee on Trade and Development,

'Special and Differential Treatment for Developing

Countries in the Multilateral Trading System:

Communication from Egypt,' T/GC/W/109;

WT/COMTD/W/49, 5 November 1998, [93].

Putra, Akbar Kurnia. "Agreement on Agricultue dalam World

Trade Organization". Jurnal Hukum dan Pembangunan

Tahun ke-46. No. 1. 1 Januari-maret 2001.

Laporan penelitian "Asas-asas Hukum Internasional Yang

Mendukung Tata Ekonomi Internasional Baru".

Kerjasama Proyek Penelitian dan Pengembangan

Politik Luar Negeri Republik Indonesia dengan Pusat

Penelitian Perkembangan Hukum Lembaga Penelitian UNPAD. Bandung. 2016.

The Doha Ministerial Conference, WT/MIN(01)/ST/10, 10 November 2001.

The Doha Ministerial Conference, WT/MIN(01)/ST/12, 10 November 2001.

The Doha Ministerial Conference, WT/MIN(01)/ST/16, 10 November 2001.

The Doha Ministerial Conference, WT/MIN(01)/ST/39 11 November 2001.

The Preamble of The Decision on Implementation-Related Issues and Concerns, WT/MIN(01)/17, [3], 20 November 2001.

The Singapore Ministerial Conference, WT/MIN(96)/ST/22, 9 Desember 1996.

The Singapore Ministerial Declaration, WT/MIN(96)/Dec, [10], 18 Desember 1996. 
The WTO Secretariat, Implementation of Special and Differential Treatment Provisions in WTO Agreements and Decisions, Committee on Trade and Development, WT/COMTD/W/77( 25 Oktober 2000).

\section{Laman}

The Millennium Development Goals Report 2014, https://www.un.org/millenniumgoals/2014\%20MDG \%20report/MDG\%202014\%20English\%20web.pdf, diakses pada 3 Juni 2020, Pukul 21.30 WIB.

United Nations Committee for Development Policy, List of Least Develop Countries, https://www.un.org/development/desa/dpad/wpcontent/uploads/sites/45/publication/ldc list.pdf, diakses pada 29 Mei 2020, Pukul 19.21 WIB. 